\title{
Swimming training prevents coronary endothelial dysfunction in ovariectomized spontaneously hypertensive rats
}

\author{
E.R.G. Claudio, S.A. Almeida, V. Mengal, G.A. Brasil, C.H. Santuzzi, R.V. Tiradentes, S.A. Gouvea, \\ N.S. Bissoli, R.L. Santos and G.R. Abreu \\ Departamento de Ciências Fisiológicas, Centro de Ciências da Saúde, Universidade Federal do Espírito Santo, Vitória, ES, Brasil
}

\begin{abstract}
Estrogen deficiency and hypertension are considered major risk factors for the development of coronary heart disease. On the other hand, exercise training is considered an effective form to prevent and treat cardiovascular diseases. However, the effects of swimming training (SW) on coronary vascular reactivity in female ovariectomized hypertensive rats are not known. We aimed to evaluate the effects of SW on endothelium-dependent coronary vasodilation in ovariectomized hypertensive rats. Threemonth old spontaneously hypertensive rats $(\mathrm{SHR}, \mathrm{n}=50)$ were divided into four groups: sham (SH), sham plus swimming training (SSW), ovariectomized (OVX), and ovariectomized plus swimming training (OSW). The SW protocol (5 times/week, $60 \mathrm{~min} /$ day) was conducted for 8 weeks. The vasodilatory response was measured in isolated hearts in the absence and presence of a nitric oxide synthase inhibitor (L-NAME, $100 \mu \mathrm{M}$ ). Cardiac oxidative stress was evaluated in situ by dihydroethidium fluorescence, while the expression of antioxidant enzymes (SOD-2 and catalase) and their activities were assessed by western blotting and spectrophotometry, respectively. Vasodilation in SHR was significantly reduced by OVX, even in the presence of L-NAME, in conjunction with an increased oxidative stress. These effects were prevented by SW, and were associated with a decrease in oxidative stress. Superoxide dismutase 2 (SOD-2) and catalase expression increased only in the OSW group. However, no significant difference was found in the activity of these enzymes. In conclusion, SW prevented the endothelial dysfunction in the coronary bed of ovariectomized SHR associated with an increase in the expression of antioxidant enzymes, and therefore may prevent coronary heart disease in hypertensive postmenopausal women.
\end{abstract}

Key words: Swimming training; Ovariectomy; Coronary reactivity; Oxidative stress; Antioxidant enzymes

\section{Introduction}

Coronary heart disease (CHD) is the main source of morbidity and mortality in the world (1), for which hypertension is considered a great risk factor (2). Hypertension causes a significant increase in the coronary vascular resistance, impairs the auto-regulatory mechanism and can cause the left ventricle (LV) dysfunction (3).

Women in their reproductive period are protected against cardiovascular diseases (CVD), mainly because of estrogens. However, the decline in estrogens production in the postmenopausal period can raise the risk for the development of hypertension and, consequently, CHD $(4,5)$. Animal studies showed that ovariectomy increases blood pressure (BP) of normotensive rats (6) and even worsens the hypertensive state of spontaneously hypertensive rats (SHR) $(7,8)$.

Oxidative stress is a common feature of hypertension and of estrogen deficiency $(6,9,10)$, and helps to promote endothelial dysfunction (11). This pathological modification in endothelial biology is of great importance because the impairment of endothelium vasodilation in human coronary circulation predicts future cardiovascular events and long-term outcomes (12).

On the other hand, exercise training (ET) has been considered an effective method to prevent or treat many CVDs. Accordingly, ET can lower BP in humans (13) and in male SHR (14), but its effects are controversial in female SHR $(15,16)$. The anti-hypertensive effects of ET have been attributed mainly to neurohumoral and structural adaptations, increased vascular responsiveness to vasodilator stimuli, or both. These responses include an increase in the plasmatic atrial natriuretic peptide concentration (14), enhancement of nitric oxide (NO) production and a decrease in angiotensin II levels (17), attenuation of arterial stiffness in ovariectomized (OVX) rats (18), and a reduction in oxidative stress (19).

Correspondence: G.R. Abreu: <abreugr1994@gmail.com>

Received June 17, 2016 | Accepted November 10, 2016 
In addition, engaging in daily ET has been shown to improve reactive hyperemia and endothelium-dependent dilation in normotensive and hypertensive human subjects by an augmented NO formation $(13,20)$.

Nevertheless, although ET may cause a reduction in $\mathrm{BP}$ in hypertensive animals, the relationship between ET and the endothelium-mediated coronary reactivity in female ovariectomized SHR is not known. This is of major importance given the potential additive effects of high BP and estrogen deficiency on the impairment of coronary circulation that may be observed in postmenopausal hypertensive women. Our hypothesis was that swimming training (SW) may prevent the endothelial dysfunction in the coronary circulation of ovariectomized SHR. Thus, the aim of this study was to evaluate the effects of 8 weeks of SW on the endothelium-mediated dilation in the coronary bed in a model of postmenopausal hypertension. Furthermore, we sought to evaluate the oxidative stress and the enzymatic antioxidant system in order to verify the adaptive responses to ET on the reactive oxygen species production.

\section{Material and Methods}

\section{Animals}

Three-month-old female spontaneously hypertensive rats $(n=50)$ were obtained from the university facility. All procedures were approved by the Institutional Ethical Committee for Animal Care and Use of the Universidade Federal do Espírito Santo, Vitória, ES, Brazil (protocol \#024/2011). Experiments were conducted in accordance with the Guide for the Care and Use of Laboratory Animals published by the US National Institutes of Health (NIH Publication, revised 1996). Animals were kept in communal cages with free access to water and standard rat chow (Purina Labina ${ }^{\circledR}$, Brazil). Temperature $\left(22-24^{\circ} \mathrm{C}\right)$, humidity $(40-60 \%)$, and light-dark cycles $(12-12 \mathrm{~h})$ were carefully controlled. At the time of ovariectomy, the animals were randomly divided into four groups as follows: sham $(\mathrm{SH})$, sham plus swimming training (SSW), ovariectomized (OVX), ovariectomized plus swimming training (OSW).

\section{Ovariectomy}

Ovariectomy was performed under anesthesia with ketamine $(80 \mathrm{mg} / \mathrm{kg}, \mathrm{ip})$ and xylazine (12 mg/kg, ip). Bilateral dorsolateral incisions were made through the skin, and the underlying muscle tissue was dissected to locate the ovaries and fallopian tubes, which were ligated with a suture line, and the ovaries were removed. The muscle and skin were then sutured with an absorbable suture. After surgery, animals received an injection of antibiotic $(2.5 \%$ enrofloxacin, $0.1 \mathrm{~mL}, \mathrm{im})$. In sham animals, the same procedure was followed but without ovariectomy. The surgery was done in all animals during the same period of the day and seven days of recovery were allowed before the start of the training protocol.

\section{Swimming training}

The swimming training was performed according to the protocol described by Kuru et al. (21), in an apparatus adapted for rats. It contained warm water $\left(30-32^{\circ} \mathrm{C}\right)$ and had a depth of $60 \mathrm{~cm}$. The training protocol was conducted during the same period of the day (4:00-6:00 pm) for all the training sessions. The first week consisted of an adaptation period, initiated with $10 \mathrm{~min}$ of continuous swimming training on the first day. Swimming time was increased daily until reaching $60 \mathrm{~min}$ at the end of the fifth day. From the second week, the exercise duration was kept constant ( $60 \mathrm{~min} /$ day, 5 days/week) with 2 days of rest. This was maintained until the end of the training period, which lasted 8 weeks. To avoid effects related to acute exercise, animals rested for $48 \mathrm{~h}$ before being sacrificed for all additional procedures (22).

\section{BP measurements}

Systolic BP (SBP) was evaluated in conscious rats before and after the training period and was determined by an indirect tail-cuff method (IITC Life Science, Inc., USA). Animals were restrained for 5-10 $\mathrm{min}$ and conditioned to the procedure with cuff inflation-deflation cycles. The results of three stable measurements of SBP were averaged. The pressure was automatically controlled and systolic pulses were detected by a pulse transducer. A suitable cuff size was selected for each animal.

\section{Isolated heart preparation (modified Langendorff method)}

To evaluate coronary perfusion pressure (CPP) and endothelium-dependent vasodilation, animals were anesthetized with chloral hydrate $(40 \mathrm{mg} / \mathrm{kg}$, ip). The rats were sacrificed by decapitation, and their hearts were immediately excised and perfused at a constant flow. Studies on the coronary vascular bed were performed on whole hearts using a Langendorff preparation (Hugo Sachs Electronics, Germany), for perfused isolated hearts $(23,24)$. Briefly, the isolated hearts were perfused with modified Krebs solution containing $120 \mathrm{mM} \mathrm{NaCl}, 1.26 \mathrm{mM} \mathrm{CaCl}_{2} \cdot 2 \mathrm{H}_{2} \mathrm{O}$, $5.4 \mathrm{mM} \mathrm{KCl}, 2.5 \mathrm{mM} \mathrm{MgSO}_{4} \cdot 7 \mathrm{H}_{2} \mathrm{O}, 2 \mathrm{mM} \mathrm{NaH}_{2} \mathrm{PO}_{4} \cdot \mathrm{H}_{2} \mathrm{O}$, $27 \mathrm{mM} \mathrm{NaHCO} 3,1.2 \mathrm{mM} \mathrm{Na}_{2} \mathrm{SO}_{4}, 30 \mu \mathrm{M}$ EDTA, and $11 \mathrm{mM}$ glucose. The solution was equilibrated with $95 \%$ oxygen and $5 \%$ carbon dioxide at a controlled pressure of $100 \mathrm{mmHg}$ to give a $\mathrm{pH}$ of 7.4. Langendorff preparations were perfused at a rate of $10 \mathrm{~mL} / \mathrm{min}$ with a peristaltic pump (MS-Reglo 4 channels; Hugo Sachs Electronics) and maintained at a temperature of $37^{\circ} \mathrm{C}$. A fluid-filled balloon was introduced into the LV and connected to a transducer (Incor, Brazil) to measure the isovolumetric cardiac force and intrinsic heart rate. The balloon was filled with a spindle syringe until it reached a pre-load of $10 \mathrm{mmHg}$. The baseline CPP was measured after a period 
of stabilization (40 min). Endothelium-dependent vasodilation was randomly analyzed by an in bolus administration of $0.1 \mathrm{~mL}$ of bradykinin (Sigma, USA) in concentrations varying between $10^{-10}$ to $10^{-6} \mathrm{M}$. To analyze the role of $\mathrm{NO}$ in the endothelium-mediated relaxation of sedentary and ovariectomized swimming-trained SHR, we perfused the isolated hearts with the non-selective nitric oxide synthase inhibitor L-NAME $(100 \mu \mathrm{M})$ for 20 min and then determined the concentration-response curve with bradykinin.

\section{Isolation of coronary arteries}

The thorax cavity was opened and the heart removed and placed in cold Krebs-Henseleit buffer containing $115 \mathrm{mM} \mathrm{NaCl}, 25 \mathrm{mM} \mathrm{NaHCO}_{3}, 4.7 \mathrm{mM} \mathrm{KCl}, 1.2 \mathrm{mM}$ $\mathrm{MgSO}_{4} \cdot 7 \mathrm{H}_{2} \mathrm{O}, 2.5 \mathrm{mM} \mathrm{CaCl}, 1.2 \mathrm{mM} \mathrm{KH}_{2} \mathrm{PO}_{4}, 11 \mathrm{mM}$ glucose, and $0.01 \mathrm{mM} \mathrm{Na}{ }_{2}$ EDTA at $\mathrm{pH} 7.4$, during the dissection procedure. The left anterior descending branch and the septal branch of the left coronary artery were isolated under a dissecting microscope (D.F. Vasconcelos M900, Brazil), freed of surrounding ventricular muscle tissue and snap frozen in liquid nitrogen. The samples were stored at $-80^{\circ} \mathrm{C}$ until their use.

\section{Detection of superoxide production (dihydroethidium fluorescence)}

Dihydroethidium (DHE) fluorescence was used to detect the superoxide production in cardiac tissue as previously described (25). We perform this in the cardiac tissue because the coronary circulation is regulated mainly under the influence of the cardiac metabolism products, including the reactive oxygen species (26). Briefly, frozen, unfixed cardiac sections were cut into 8-mm thick sections and mounted on gelatin-coated glass slides. Then, the samples were incubated with the oxidative fluorescent dye DHE (2 $\mathrm{mM}$ ) in a modified Krebs' solution (containing $20 \mathrm{mM}$ HEPES), in a light-protected humidified chamber at $37^{\circ} \mathrm{C}$ for $30 \mathrm{~min}$, to detect superoxide. The fluorescence intensity was detected at $585 \mathrm{~nm}$ and quantified using a confocal fluorescence microscope (Leica DM 2500 TI, Nikon Instruments Inc., USA) by a technician completely blind to the experimental protocol. Analysis of 10 fields per sample was performed.

\section{Western blotting}

Coronary samples were homogenized in a lysis buffer containing $150 \mathrm{mM} \mathrm{NaCl}, 50 \mathrm{mM}$ Tris- $\mathrm{HCl}, 5 \mathrm{mM} \mathrm{Na}{ }_{2}$ EDTA, and $1 \mathrm{mM} \mathrm{MgCl}$, plus a protease inhibitor (Sigma Fast; Sigma). Protein concentration was determined by the Lowry method (27) and bovine serum albumin (BSA) was used as the standard. The same amount of proteins $(50 \mu \mathrm{g})$ were denatured and separated by SDS-PAGE (10\%) and transferred onto a PVDF membrane (Millipore, Germany). Membranes were blocked with 5\% BSA at room temperature in a TBS buffer plus Tween $20(0.1 \%)$ before incubation with polyclonal anti-mouse antibody for Mn-superoxide dismutase 2 (SOD-2; 1:1000-Sigma), monoclonal anti-mouse antibody for catalase (1:2000Sigma), and polyclonal anti-mouse antibody for $\beta$-actin (1:1500-Sigma). After washing, the membranes were incubated with an alkaline phosphatase conjugated antimouse IgG (1:3000, Abcam Inc., USA). The bands were visualized using an NBT/BCIP system (Invitrogen Corporation, USA) and quantified using ImageJ software (National Institute of Health, USA).

\section{Antioxidant enzyme activity}

SOD activity in cardiac tissue was assessed according to the Misra and Fridovich method (28). Briefly, $0.1 \mathrm{~mL}$ of homogenate $(0.25 \mathrm{mg} / \mathrm{mL})$ was added to a quartz cuvette containing $1.0 \mathrm{~mL}$ of carbonate buffer $(0.2 \mathrm{M}, \mathrm{pH} 10.2)$, $0.8 \mathrm{~mL}$ of $\mathrm{KCl}(0.015 \mathrm{M})$. Total volume was completed to $3.0 \mathrm{~mL}$ with deionized water. The reaction was initiated by the addition of epinephrine $(0.025 \mathrm{M})$ and the inhibition of autocatalytic adrenochrome formation rate was measured. Measurements were made spectrophotometrically at $480 \mathrm{~nm}$. The enzymatic activity is reported as units of SOD/mg protein. Catalase enzyme activity was measured in the supernatants as described by Nelson and Kiesow (29). Briefly, $0.04 \mathrm{~mL}$ of $\mathrm{H}_{2} \mathrm{O}_{2}$ was added as a substrate to $0.06 \mathrm{~mL}$ of homogenate and $1.9 \mathrm{~mL}$ of potassium phosphate buffer (50 mM, pH 7.0) to give a final $\mathrm{H}_{2} \mathrm{O}_{2}$ concentration of $6 \mathrm{mM}$. The reaction proceeded for $1 \mathrm{~min}$ at room temperature. Decomposition of $\mathrm{H}_{2} \mathrm{O}_{2}$ by catalase was determined by the variation in absorbance at $240 \mathrm{~nm}$ $(\Delta \mathrm{E})$. Measurements were performed in duplicate. The enzymatic activity is reported as millimoles of $\mathrm{H}_{2} \mathrm{O}_{2}$ decomposed per minute per milligram of protein $\left(\Delta \mathrm{E} \cdot \mathrm{min}^{-1} \cdot \mathrm{mg}\right.$ $\left.\operatorname{protein}^{-1}\right)$.

\section{Citrate synthase activity}

Citrate synthase activity was measured as previously described (25). Briefly, samples of soleus muscle were homogenized in phosphate buffer $(50 \mathrm{mM}$ sodium phosphate, $1 \mathrm{mM}$ EDTA and protease inhibitor cocktail

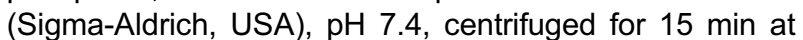
$12,000 \mathrm{~g}$ and $4^{\circ} \mathrm{C}$ and the pellet was then discarded. The supernatant was used for the assay. The assay mixture contained $100 \mathrm{mM}$ Tris, $1 \mathrm{mM}$ EDTA, $0.2 \mathrm{mM}$ DTNB, $0.1 \mathrm{mM}$ Acetyl-CoA, 1\% (v/v) Triton X-100, sample (130 mg of soluble proteins per $\mathrm{mL}$ of total assay) and $0.5 \mathrm{mM}$ oxaloacetate (added last). The absorbance was monitored at $412 \mathrm{~nm}$ in a 96 -well plate for $10 \mathrm{~min}$ at $25^{\circ} \mathrm{C}$, and maximal citrate synthase activity was measured within the linear range of the assay.

\section{Statistical analysis}

Data are reported as means $\pm S E$. A paired Student's $t$-test and one- and two-way ANOVA were used, when appropriate. The differences among groups found by ANOVA were tested with the Fisher's post hoc tests for multiple comparisons. Statistical significance was set at $\mathrm{P}<0.05$. 


\section{Results}

Body weight, estrogen status, cardiac weight and citrate synthase activity

Body weight was significantly increased by ovariectomy and was not altered by ET in female SHR. Uterus weight (UW) and the ratio of UW to body weight (BW) were used to evaluate the estrogen status. As expected, there was a significant decrease in both parameters in OVX animals $(\mathrm{P}<0.05)$. Heart weight $(\mathrm{HW})$ and LV weight (LVW) were not significantly altered by ovariectomy or by swimming training, even when adjusted by body weight. In order to analyze the effectiveness of our swimming training protocol, we measured the citrate synthase enzyme activity of soleus muscle samples. The results showed a significant increase in the enzymatic activity of both trained groups compared to the sedentary groups $(P<0.05$, Table 1$)$.

\section{Systolic BP, baseline CPP and vasodilatory response to bradykinin}

Systolic BP was not different between the groups at baseline. However, when the initial and final SBP within each group was compared, we observed a significant increase in the final SBP only in the OVX group $(P<0.05)$, suggesting that ET is able to prevent the worsening of hypertension, which occurs with estrogen deficiency.

The baseline CPP was not different among groups. After incubation with L-NAME, CPP increased significantly in all of the groups studied but no differences between the groups were detected, demonstrating that NO has a major role in the maintenance of tonus in the arterial coronary bed regardless of the presence of estrogens and/or ET (Table 2). However, OVX caused a significant impairment in the vasodilation induced by bradykinin, when compared to sham-operated animals. ET prevented the impairment caused by OVX, and that group was able to maintain the same level of vasodilation as observed in the sham group (Figure 1A). When the L-NAME was perfused in the hearts (Figure 1B), the endothelium-mediated responses were profoundly reduced in all groups. In OVX rats, this response was almost abolished. However, the differences between the groups were maintained.

\section{Superoxide production, antioxidant enzyme expression and activity}

Superoxide production, assessed by DHE fluorescence (Figure 2), showed that OVX animals had an augmented oxidative stress compared with the sham groups $(\mathrm{P}<0.05)$.

Table 1. Body weight, estrogen status, and cardiac weight.

\begin{tabular}{lcccc}
\hline & SH & SSW & OVX & OSW \\
\hline BW final (g) & $191.3 \pm 2.03(12)$ & $196 \pm 5.22(12)$ & $214.8 \pm 5.22(13)^{\star \#}$ & $213.8 \pm 3.63(13)^{\star \#}$ \\
UW (mg) & $638.6 \pm 81.27(12)$ & $590 \pm 86.96(12)$ & $171.9 \pm 23.32(13)^{\star \#}$ & $165 \pm 37.9(13)^{\star \#}$ \\
UW/BW (mg/g) & $3.36 \pm 0.48(12)$ & $3.03 \pm 0.46(12)$ & $0.80 \pm 0.10(13)^{\star \#}$ & $0.75 \pm 0.17(13)^{\star \#}$ \\
HW $(\mathrm{mg})$ & $1200 \pm 83.54(12)$ & $1131 \pm 96.28(12)$ & $1137 \pm 51.39(13)$ & $1254 \pm 83.83(13)$ \\
HW/BW (mg/g) & $6.20 \pm 0.52(12)$ & $5.80 \pm 0.56(12)$ & $5.25 \pm 0.23(13)$ & $5.71 \pm 0.28(13)$ \\
LV (mg) & $781.2 \pm 57.31(12)$ & $775.1 \pm 60.21(12)$ & $804.5 \pm 30.39(13)$ & $810.5 \pm 42.44(13)$ \\
LV/BW $(\mathrm{mg} / \mathrm{g})$ & $4.08 \pm 0.29(12)$ & $3.96 \pm 0.31(12)$ & $3.71 \pm 0.12(13)$ & $3.70 \pm 0.12(13)$ \\
CSA $\left(\mu \mathrm{mol} \cdot \mathrm{mg}^{-1} \cdot \mathrm{min}^{-1}\right)$ & $7024 \pm 403(4)$ & $12147 \pm 523(4)^{\star^{\star}}$ & $7225 \pm 759(5)$ & $11605 \pm 2366(4)^{\star^{\S}}$ \\
\hline
\end{tabular}

Data are reported as means $\pm \mathrm{SE}$, with number in parentheses. $\mathrm{SH}$ : sham-operated; SSW: sham plus swimming training; OVX: ovariectomized; OSW: ovariectomized plus swimming training. BW: body weight; UW: uterine weight; HW: heart weight; LV: left ventricle; CSA: citrate synthase activity. ${ }^{*} \mathrm{P}<0.05$ vs SH; ${ }^{\#} \mathrm{P}<0.05$ vs SSW; ${ }^{\mathrm{P}}<0.05$ vs OVX (one-way ANOVA followed by the Fisher's post hoc test).

Table 2. Blood pressure, coronary perfusion pressure, and intrinsic heart rate.

\begin{tabular}{lllll}
\hline & \multicolumn{1}{c}{ SH } & \multicolumn{1}{c}{ SSW } & OVX & OSW \\
\hline SBP initial (mmHg) & $174 \pm 6.71(8)$ & $181 \pm 12(6)$ & $170 \pm 3.81(9)$ & $184 \pm 4.09(6)$ \\
SBP final (mmHg) & $185 \pm 2.32(8)$ & $173 \pm 5.98(6)^{\star}$ & $192 \pm 2.92(9)^{\#^{+}}$ & $186 \pm 1.21(6)^{\#}$ \\
Baseline CPP (mmHg) & $132 \pm 4(6)$ & $113 \pm 11(6)$ & $108 \pm 6(6)$ & $116 \pm 2(6)$ \\
CPP after L-NAME (mmHg) & $201 \pm 9(6)^{\ddagger}$ & $168 \pm 12(6)^{\ddagger}$ & $195 \pm 9(6)^{\ddagger}$ & $185 \pm 12(6)^{\ddagger}$ \\
IHR (bpm) & $237 \pm 8(6)$ & $209 \pm 17(6)^{\S}$ & $278 \pm 15(6)$ & $231 \pm 10(6)^{\ddagger}$ \\
\hline
\end{tabular}

Data are reported as means $\pm \mathrm{SE}$, with number in parentheses. $\mathrm{SH}$ : sham-operated; SSW: sham plus swimming training; OVX: ovariectomized; OSW: ovariectomized plus swimming training. SBP; systolic blood pressure; CPP: coronary perfusion pressure; IHR: intrinsic heart rate. ${ }^{\$} \mathrm{P}<0.05$ vs OVX; ${ }^{+} \mathrm{P}<0.05$ vs SBP initial within group; ${ }^{\dagger} \mathrm{P}<0.05$ vs baseline CPP within group. One-way ANOVA followed by the Fisher's post hoc test was used for multiple comparisons and the paired Student's $t$-test was used for comparisons between SBP initial vs SBP final and baseline CPP vs CPP after L-NAME within groups. 

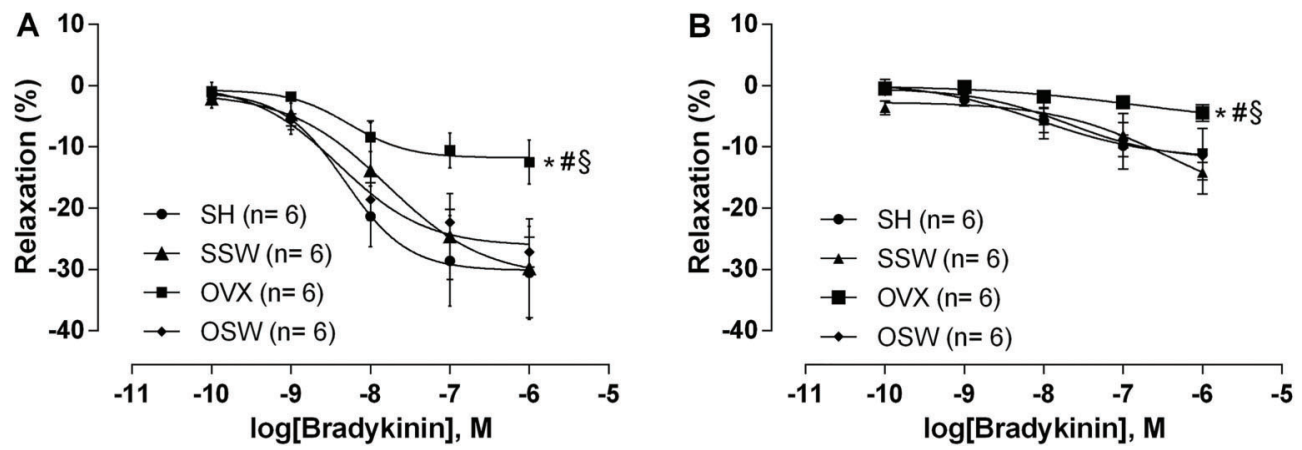

Figure 1. Endothelium-dependent vasodilator response to bradykinin. A, Estrogen deficiency in spontaneously hypertensive rats led to endothelial dysfunction, which was prevented by 8 weeks of swimming training. $B$, Pre-incubation with nitric oxide synthase inhibitor (L-NAME, $100 \mu \mathrm{M}$ ) reduced the endothelium-dependent vasodilation in all groups. SH: sham-operated; SSW: sham plus swimming training; OVX: ovariectomized; OSW: ovariectomized plus swimming training. Data are reported as means $\pm \mathrm{SE}$. ${ }^{*} \mathrm{P}<0.05$ vs $\mathrm{SH}$, ${ }^{\#} \mathrm{P}<0.05$ vs SSW, and ${ }^{\S} \mathrm{P}<0.05$ vs OSW (two-way ANOVA followed by Fisher's post hoc test).
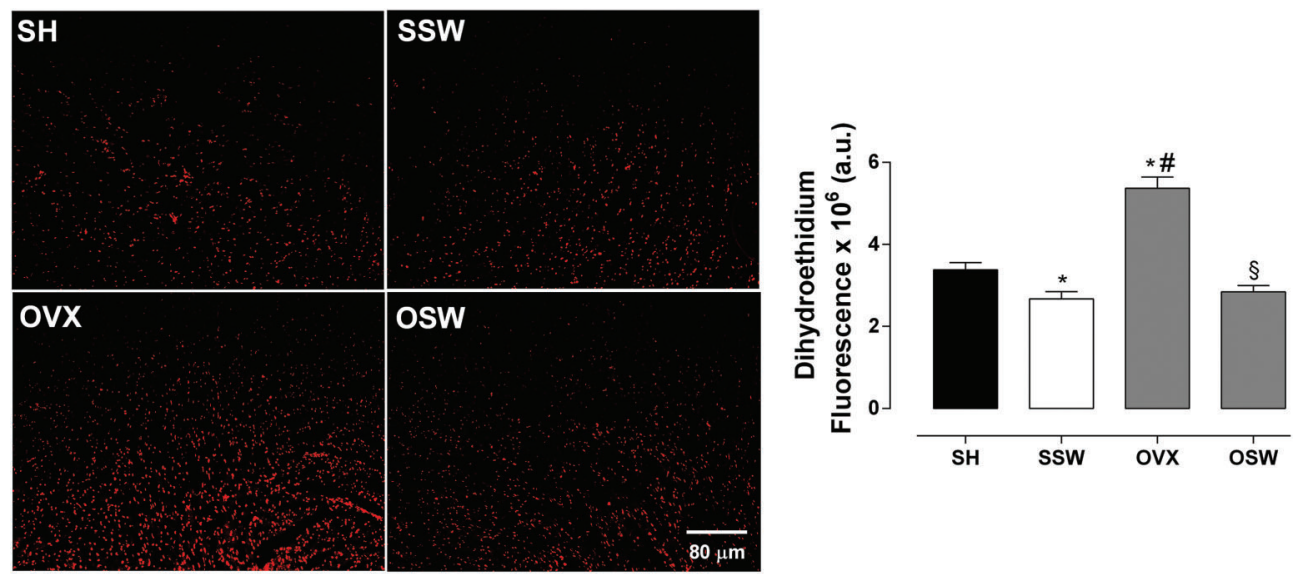

Figure 2. Analysis of superoxide production in cardiac sections by the dihydroethidium fluorescence. SH: sham-operated; SSW: sham plus swimming training; OVX: ovariectomized; OSW: ovariectomized plus swimming training. Data are reported as means $\pm S E$ for $n=4$ animals per group. ${ }^{*} \mathrm{P}<0.05$ vs SH, ${ }^{\#} \mathrm{P}<0.05$ vs SSW, and ${ }^{\$} \mathrm{P}<0.05$ vs OVX (one-way ANOVA followed by Fisher's post hoc test).

However, ET prevented the increase in reactive oxygen species (ROS) production in OVX hypertensive rats $(\mathrm{P}<0.05$ vs OVX), demonstrating the antioxidant effects of ET. The expression of antioxidant enzymes SOD-2 and catalase in coronary arteries and the activity of these enzymes in cardiac tissue were verified to determine the possible effect of antioxidant adaptation in the vasodilation promoted by ET. The expression of SOD-2 (Figure 3A), the enzyme that catalyses the dismutation of the superoxide anion $(\mathrm{O} 2 \cdot)$ to $\mathrm{H}_{2} \mathrm{O}_{2}$, and the expression of catalase (Figure 3B), which decomposes $\mathrm{H}_{2} \mathrm{O}_{2}$ into water and oxygen, increased significantly in the OSW group compared to the OVX group $(P<0.05)$, suggesting that their expression in coronary arteries are regulated by ETinduced oxidative stress. However, differences among the groups in the cardiac activity of these enzymes were not detected (Figure 4A and B), suggesting that the expression of these enzymes is the major antioxidant adaptation promoted by ET in the absence of estradiol in ovariectomized SHR.

\section{Discussion}

The major results of this study were: 1) OVX impaired endothelium-mediated vasodilation in hypertensive rats, which may be associated with an increase in ROS production; 2) engaging in chronic SW can prevent the endothelial dysfunction that is promoted by the OVX, and 3 ) the prevention of endothelial dysfunction and oxidative stress observed in hypertensive OVX rats could be mediated by antioxidant effects through increases in coronary expression of SOD-2 and catalase, which could lead to a reduction in oxidative stress, but increases were not observed in the cardiac activities of these enzymes.

Hypertension is an important cardiovascular risk factor, which can lead to significant impairment in the regulation of 

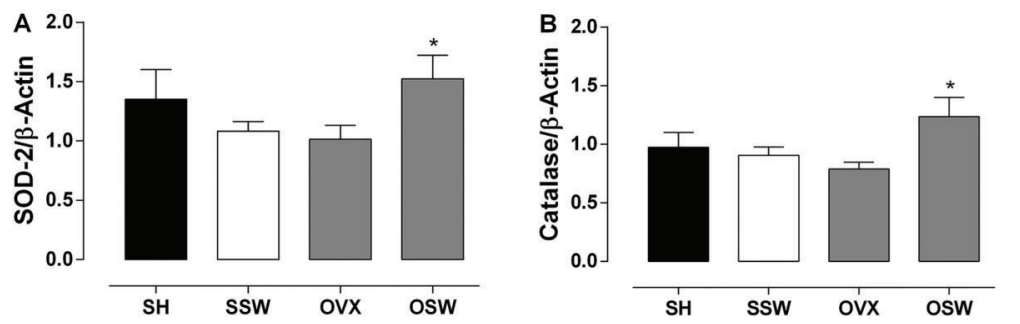

C

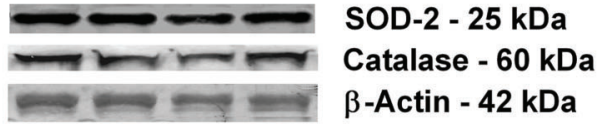

Figure 3. Protein expression of antioxidant enzymes. $A$, Mitochondrial isoform of superoxide dismutase (SOD-2) expression in coronary arteries; $B$, catalase protein expression in coronary arteries, and $C$, representative images of SOD-2, catalase, and $\beta$-actin membranes. SW induced an up-regulation in the expression of both enzymes in the OSW group compared to OVX ( ${ }^{*}<0.05$ ). SH: sham-operated; SSW: sham plus swimming training; OVX: ovariectomized; OSW: ovariectomized plus swimming training. Data are reported as means \pm SE (SH: $n=6$, SSW: $n=6$, OVX: $n=7$, OSW: $n=7$ ). One-way ANOVA followed by Fisher's post hoc test were used for statistical analyses.
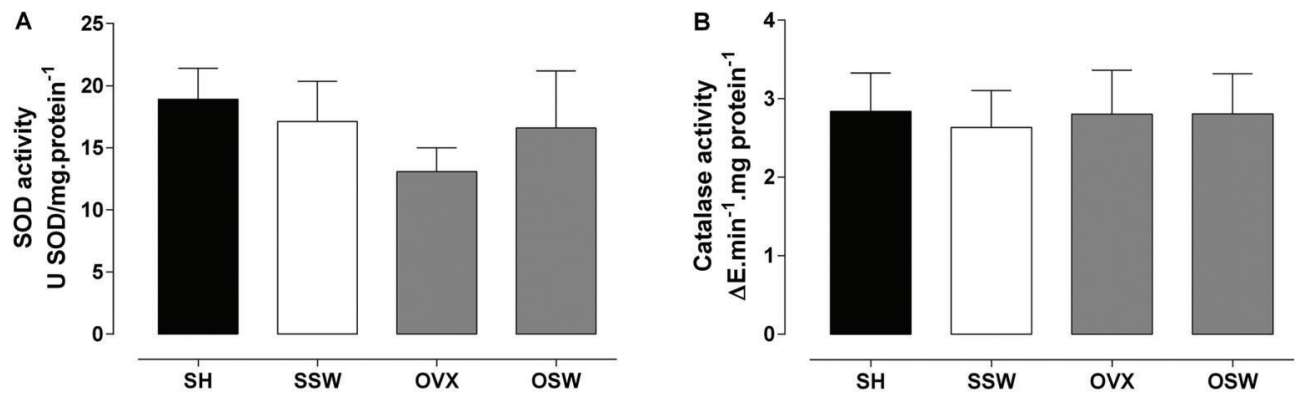

Figure 4. Enzymatic activity of antioxidant enzymes superoxide dismutase (SOD) $(A)$ and catalase $(B)$ in cardiac tissue. There were no differences among the groups. SH: sham-operated; SSW: sham plus swimming training; OVX: ovariectomized; OSW: ovariectomized plus swimming training. Data are reported as means \pm SE $(S H: n=4$, SSW: $n=5, O V X: n=5, O S W: n=5)$. $P>0.05$ (one-way ANOVA followed by Fisher's post hoc test).

coronary circulation. Furthermore, menopause can increase the incidence of CVD because of a reduction in the 17 $\beta$ estradiol concentrations (1). This reduction can also worsen the degree of hypertension in $\operatorname{SHR}(7,8,16)$, as also demonstrated in our study. Hormone therapy is a treatment commonly used to relieve symptoms associated with menopause and also to prevent CVD. Nevertheless, although studies conducted in animal models have demonstrated the beneficial effects of this therapy on the cardiovascular system $(6,23)$, large clinical trials did not demonstrate such effects $(30,31)$. Thus, the need for other treatment options is of great importance for women during this period due to the high morbidity associated with CHD.

Accordingly, the practice of ET may be an alternative to hormone therapy as many cardiovascular and metabolic benefits have been reported to be associated with regular ET. In this study, although no reduction was observed, SW prevented the worsening of hypertension in both shamoperated and ovariectomized SHR. These results are in agreement with the study of Coimbra et al. (15), which could not detect changes in BP and structural changes in the arteries and heart of hypertensive and ovariectomized animals that trained on a motorized treadmill. Another study (16) demonstrated a hypotensive effect of ET, using a 13-week treadmill training protocol, which was associated with prevention of remodeling in the heart and in the aorta wall.

However, the absence of a decrease in BP and the maintenance of basal coronary perfusion pressure did not significantly alter the occurrence of vascular adaptations to ET. Supporting our hypothesis, SW prevented the impairment of endothelium-dependent vasodilation induced by OVX in SHR rats, with vasodilation remaining at similar levels to those found in the $\mathrm{SH}$ group.

In normotensive Wistar rats, 8 weeks of ET not only prevented the coronary endothelial dysfunction of OVX rats, but it also produced a greater response compared to sham-operated animals and those submitted to estrogen therapy (23). Other studies have shown that ET can actually prevent endothelial dysfunction. In male SHR, Roque et al. (32) found that ET on a treadmill can improve endothelial function in isolated coronary arteries and small mesenteric arteries associated with a decrease in oxidative stress and arterial stiffening. In humans, the regular practice of aerobic exercises increases endothelium-derived relaxation stimulated by acetylcholine in both normotensive and hypertensive patients by increasing the release of NO (20). Therefore, according to these results, it can be stated that $\mathrm{ET}$, regardless of the modality practiced and the existence of 
cardiovascular disease, is a potent stimulus for the improvement and/or maintenance of endothelial function.

To assess the role of $\mathrm{NO}$ on the vasodilatory responses stimulated by bradykinin, we inhibited the enzyme nitric oxide synthase. A significant reduction in vasodilation in all groups was found and the difference between the OVX group and the other groups was maintained. These results suggest that NO plays a key role in the endothelium-dependent vasodilator response even with the estrogen deficiency and that endothelial dysfunction caused by OVX occurs through other mechanisms than the reduction of NO production, such as an increase in oxidative stress, which could impair the vasodilation mediated by $\mathrm{NO}(33,34)$, prostacyclin $(35)$ and endothelium-derived hyperpolarizing factor (36).

The adaptations induced by ET in relation to antioxidant enzymes in OVX hypertensive rats in our study seem to be primarily mediated by the increase in the expression of the enzymes rather than in their activity. Therefore, this seems to be a major mechanism responsible for the reduction of cardiovascular oxidative stress induced by a long-term ET in this model of postmenopausal hypertension. Consistent with these data, in a previous

\section{References}

1. Wenger NK. Coronary heart disease: an older woman's major health risk. BMJ 1997; 315: 1085-1090, doi: 10.1136/ bmj.315.7115.1085.

2. Kearney PM, Whelton M, Reynolds K, Muntner P, Whelton $\mathrm{PK}, \mathrm{He} \mathrm{J}$. Global burden of hypertension: analysis of worldwide data. Lancet 2005; 365: 217-223, doi: 10.1016/S01406736(05)70151-3.

3. Harrison DG, Florentine MS, Brooks LA, Cooper SM, Marcus $M L$. The effect of hypertension and left ventricular hypertrophy on the lower range of coronary autoregulation. Circulation 1988; 77: 1108-1115, doi: 10.1161/01.CIR.77.5.1108.

4. Staessen JA, Celis H, Fagard R. The epidemiology of the association between hypertension and menopause. J Hum Hypertens 1998; 12: 587-592, doi: 10.1038/sj.jhh.1000670.

5. Barton M, Meyer MR. Postmenopausal hypertension: mechanisms and therapy. Hypertension 2009; 54: 11-18, doi: 10.1161/HYPERTENSIONAHA.108.120022.

6. Hernandez I, Delgado JL, Diaz J, Quesada T, Teruel MJ, Llanos MC, et al. 17beta-estradiol prevents oxidative stress and decreases blood pressure in ovariectomized rats. $A m \mathrm{~J}$ Physiol Regul Integr Comp Physiol 2000; 279: R1599R1605.

7. Silva-Antonialli MM, Tostes RC, Fernandes L, Fior-Chadi $\mathrm{DR}$, Akamine $\mathrm{EH}$, Carvalho $\mathrm{MH}$, et al. A lower ratio of AT1/AT2 receptors of angiotensin II is found in female than in male spontaneously hypertensive rats. Cardiovasc Res 2004; 62: 587-593, doi: 10.1016/j.cardiores.2004.01.020.

8. Borgo MV, Lopes AB, Gouvea SA, Romero WG, Moyses $\mathrm{MR}$, Bissoli NS, et al. Effect of tamoxifen on the coronary vascular reactivity of spontaneously hypertensive female rats. Braz J Med Biol Res 2011; 44: 786-792, doi: 10.1590/ S0100-879X2011007500099. study from our laboratory with normotensive ovariectomized rats, we observed an increase in the expression of antioxidant enzymes SOD-1 and catalase in the coronary arteries (23). These results are of major importance for improving endothelial function because the model used in this study displays two components that are widely associated with oxidative stress, such as the estrogen deficiency and hypertension.

In conclusion, SW prevents endothelial dysfunction in coronary arteries observed in a model of postmenopausal hypertension. The increase in the expression of antioxidant enzymes seems to be the main factor related to the vascular adaptations promoted by the practice of SW, reducing the oxidative stress and augmenting the bioavailability of NO. Thus, the practice of ET can prevent endothelial dysfunction, and consequently, reduce the risk of $\mathrm{CHD}$ in hypertensive postmenopausal women.

\section{Acknowledgments}

E.R.G. Claudio was supported by a fellowship from Coordenação de Aperfeiçoamento de Pessoal de Nível Superior (CAPES).

9. Yanes L, Romero D, lliescu R, Cucchiarelli VE, Fortepiani LA, Santacruz F, et al. Systemic arterial pressure response to two weeks of Tempol therapy in SHR: involvement of NO, the RAS, and oxidative stress. Am J Physiol Regul Integr Comp Physiol 2005; 288: R903-R908, doi: 10.1152/ajpregu. 00530.2004

10. Sanchez-Rodriguez MA, Zacarias-Flores M, ArronteRosales A, Correa-Munoz E, Mendoza-Nunez VM. Menopause as risk factor for oxidative stress. Menopause 2012; 19: 361-367, doi: 10.1097/gme.0b013e318229977d.

11. Cai H, Harrison DG. Endothelial dysfunction in cardiovascular diseases: the role of oxidant stress. Circ Res 2000; 87: 840-844, doi: 10.1161/01.RES.87.10.840.

12. Schachinger $V$, Britten MB, Zeiher AM. Prognostic impact of coronary vasodilator dysfunction on adverse long-term outcome of coronary heart disease. Circulation 2000; 101: 1899-1906, doi: 10.1161/01.CIR.101.16.1899.

13. Higashi $Y$, Sasaki S, Sasaki N, Nakagawa K, Ueda T, Yoshimizu A, et al. Daily aerobic exercise improves reactive hyperemia in patients with essential hypertension. Hypertension 1999; 33: 591-597, doi: 10.1161/01.HYP.33.1.591.

14. Endlich PW, Firmes LB, Goncalves WL, Gouvea SA, Moyses $\mathrm{MR}$, Bissoli NS, et al. Involvement of the atrial natriuretic peptide in the reduction of arterial pressure induced by swimming but not by running training in hypertensive rats. Peptides 2011; 32: 1706-1712, doi: 10.1016/j.peptides. 2011.06.027.

15. Coimbra R, Sanchez LS, Potenza JM, Rossoni LV, Amaral SL, Michelini LC. Is gender crucial for cardiovascular adjustments induced by exercise training in female spontaneously hypertensive rats? Hypertension 2008; 52: 514-521, doi: 10.1161/HYPERTENSIONAHA.108.114744. 
16. Marques CM, Nascimento FA, Mandarim-de-Lacerda CA, Aguila MB. Exercise training attenuates cardiovascular adverse remodeling in adult ovariectomized spontaneously hypertensive rats. Menopause 2006; 13: 87-95, doi: 10.1097/ 01.gme.0000191209.13115.46.

17. Kohno H, Furukawa S, Naito H, Minamitani K, Ohmori D, Yamakura F. Contribution of nitric oxide, angiotensin II and superoxide dismutase to exercise-induced attenuation of BP elevation in spontaneously hypertensive rats. Jpn Heart $J$ 2001; 43: 25-34, doi: 10.1536/jhj.43.25.

18. Park JH, lemitsu M, Maeda S, Kitajima A, Nosaka T, Omi N. Voluntary running exercise attenuates the progression of endothelial dysfunction and arterial calcification in ovariectomized rats. Acta Physiol 2008; 193: 47-55, doi: 10.1111/ j.1748-1716.2007.01799.x.

19. Kimura $\mathrm{H}$, Kon N, Furukawa $S$, Mukaida M, Yamakura F, Matsumoto $\mathrm{K}$, et al. Effect of endurance exercise training on oxidative stress in spontaneously hypertensive rats (SHR) after emergence of hypertension. Clin Exp Hypertens 2010; 32: 407-415, doi: 10.3109/10641961003667930.

20. Higashi Y, Sasaki S, Kurisu S, Yoshimizu A, Sasaki N, Matsuura $\mathrm{H}$, et al. Regular aerobic exercise augments endothelium-dependent vascular relaxation in normotensive as well as hypertensive subjects: role of endothelium-derived nitric oxide. Circulation 1999; 100: 1194-1202, doi: 10.1161/ 01.CIR.100.11.1194.

21. Kuru O, Senturk UK, Kocer G, Ozdem S, Baskurt OK, Cetin $A$, et al. Effect of exercise training on resistance arteries in rats with chronic NOS inhibition. J Appl Physiol 2009; 107: 896-902, doi: 10.1152/japplphysiol.91180.2008.

22. Liu J, Yeo HC, Overvik-Douki E, Hagen T, Doniger SJ, Chyu DW, et al. Chronically and acutely exercised rats: biomarkers of oxidative stress and endogenous antioxidants. J Appl Physiol 2000; 89: 21-28.

23. Claudio ER, Endlich PW, Santos RL, Moyses MR, Bissoli NS, Gouvea SA, et al. Effects of chronic swimming training and oestrogen therapy on coronary vascular reactivity and expression of antioxidant enzymes in ovariectomized rats. PLoS One 2014; 8: e64806, doi: 10.1371/journal.pone. 0064806.

24. Santos RL, Abreu GR, Bissoli NS, Moyses MR. Endothelial mediators of 17 beta-estradiol-induced coronary vasodilation in the isolated rat heart. Braz J Med Biol Res 2004; 37: 569-575, doi: 10.1590/S0100-879X2004000400014.

25. Almeida SA, Claudio ER, Mengal V, Oliveira SG, Merlo E, Podratz PL, et al. Exercise training reduces cardiac dysfunction and remodeling in ovariectomized rats submitted to myocardial infarction. PLoS One 2014; 9: e115970, doi: 10.1371/journal.pone.0115970.
26. Saitoh S, Zhang C, Tune JD, Potter B, Kiyooka T, Rogers PA, et al. Hydrogen peroxide: a feed-forward dilator that couples myocardial metabolism to coronary blood flow. Arterioscler Thromb Vasc Biol 2006; 26: 2614-2621, doi: 10.1161/01.ATV.0000249408.55796.da.

27. Lowry HO, Rosebrough NJ, Farr AL, Randall RJ. Protein measurement with the folin phenol reagent. $J$ Biol Chem 1958; 193: 265-275.

28. Misra HP, Fridovich I. The role of superoxide anion in the autoxidation of epinephrine and a simple assay for superoxide dismutase. J Biol Chem 1972; 247: 3170-3175.

29. Nelson DP, Kiesow LA. Enthalpy of decomposition of hydrogen peroxide by catalase at 25 degrees $\mathrm{C}$ (with molar extinction coefficients of $\mathrm{H}_{2} \mathrm{O}_{2}$ solutions in the UV). Anal Biochem 1972; 49: 474-478, doi: 10.1016/0003-2697(72) 90451-4.

30. Hsia J, Langer RD, Manson JE, Kuller L, Johnson KC, Hendrix SL, et al. Conjugated equine estrogens and coronary heart disease: the Women's Health Initiative. Arch Intern Med 2006; 166: 357-365, doi: 10.1001/archinte. 166.3.357.

31. Simon JA, Hsia J, Cauley JA, Richards C, Harris F, Fong J, et al. Postmenopausal hormone therapy and risk of stroke: The Heart and Estrogen-progestin Replacement Study (HERS). Circulation 2001; 103: 638-642, doi: 10.1161/01. CIR.103.5.638.

32. Roque FR, Briones AM, Garcia-Redondo AB, Galan M, Martinez-Revelles S, Avendano MS, et al. Aerobic exercise reduces oxidative stress and improves vascular changes of small mesenteric and coronary arteries in hypertension. $\mathrm{Br} \mathrm{J}$ Pharmacol 2013; 168: 686-703, doi: 10.1111/j.1476-5381. 2012.02224.x.

33. Forstermann U. Nitric oxide and oxidative stress in vascular disease. Pflugers Arch 2010; 459: 923-939, doi: 10.1007/ s00424-010-0808-2.

34. Vasquez-Vivar J, Kalyanaraman B, Martasek P, Hogg N, Masters BS, Karoui $\mathrm{H}$, et al. Superoxide generation by endothelial nitric oxide synthase: the influence of cofactors. Proc Natl Acad Sci U S A 1998; 95: 9220-9225, doi: 10.1073/ pnas.95.16.9220.

35. Zou MH, Ullrich V. Peroxynitrite formed by simultaneous generation of nitric oxide and superoxide selectively inhibits bovine aortic prostacyclin synthase. FEBS Lett 1996; 382: 101-104, doi: 10.1016/0014-5793(96)00160-3.

36. Liu Y, Terata K, Chai Q, Li H, Kleinman LH, Gutterman DD. Peroxynitrite inhibits $\mathrm{Ca}^{2+}$-activated $\mathrm{K}^{+}$channel activity in smooth muscle of human coronary arterioles. Circ Res 2002; 91: 1070-1076, doi: 10.1161/01.RES.0000046003. 14031.98 . 